\title{
Differential host utilisation by different life history stages of the fish ectoparasite Argulus foliaceus (Crustacea: Branchiura)
}

\author{
Peter D. Walker ${ }^{1,2}$, Jack E. Harris ${ }^{1}$, Gerard van der Velde ${ }^{2,3}$ and Sjoerd E. Wendelaar Bonga ${ }^{2}$ \\ ${ }^{1}$ School of Biological Sciences, University of Plymouth, Drake Circus, Plymouth PL4 8AA, UK; \\ ${ }^{2}$ Department of Animal Ecology and Ecophysiology, Institute for Water and Wetland Research, Faculty of Science, Radboud \\ University Nijmegen, Toernooiveld 1, 6525 ED, Nijmegen, The Netherlands; \\ ${ }^{3}$ National Museum of Natural History, Naturalis, P.O. Box 9517, 2300 RA, Leiden, The Netherlands
}

Key words: Argulus, ectoparasite, fish, host-choice, specificity

\begin{abstract}
In this study we examine differences in the occurrence of life history stages of the destructive fish ectoparasite Argulus foliaceus (L., 1758) on eight fish species (stickleback, rudd, roach, gudgeon, bream, tench, crucian carp and common carp) sampled from a mixed-species recreational fishing lake on nine occasions during late spring and summer. Total numbers of $A$. foliaceus, as well as the number of larval, juvenile and adult parasite stages, from each fish were recorded along with the fish species. Lice generally exhibited an aggregated distribution approximating a negative binomial distribution. Significant differences in the prevalence, intensity and intensity frequency distribution were observed between life history stages and between host species. In general, all life history stages of $A$. foliaceus exhibited an over-dispersed distribution. However, larval lice did show some degree of aggregation particularly within the stickleback samples. Infection data for parasite larval stages suggested that sticklebacks are more likely to be infected than other host species. For adult lice, however, carp appeared to be the main host. We propose that $A$. foliaceus infection characteristics are predominantly determined by the level of host exposure to the parasite and its life history stages (larval, juvenile and adult) rather than by an innate difference in host susceptibility related to individual host factors such as immune responses. We conclude that host exposure is determined by the parasite-host behavioural interplay related to species-specific ecology and behavioural traits such as microhabitat preference and normal swimming speed.
\end{abstract}

The ecology of freshwater macrophytes, planktonic organisms and macro-invertebrates is currently well described but common parasites are still poorly studied. There is a plethora of published material relating to fish parasites (e.g. Kabata 1985, Barber et al. 2000, Nolan et al. 2000, Benz et al. 2001) but the majority of these papers have focussed upon cultured and laboratory-reared host-parasite models. Considerably less published data are available on ectoparasite ecology and infection dynamics in wild populations.

Host-specificity has always been an area of interest for parasitologists as many parasite species show high levels of specificity, typically being restricted to just one species or genus (Roberts and Janovy 1996). Intermittent parasites appear to be an exception to this trend with several groups exhibiting relatively low specificity, e.g., many fleas, leeches, mosquitoes and midges. The fish louse Argulus foliaceus (L., 1758) seems to share this non-host-specific trait with other intermittent parasites as it has been reported on a wide range of freshwater fish species (Gurney 1948, Kollatsch 1959, Stammer 1959, Kennedy 1974, Lester and Roubal 1995, Holland and Kennedy 1997, Kearn 2004, Walker et al. 2004).

Many authors have commented on the lack of specificity of argulid parasites, sharing the opinion that individual species from this group (e.g., $A$. foliaceus and $A$. japonicus Thiele, 1900) can infect a wide range of host species (Kearn 2004 and references therein, Walker et al. 2004 and references therein). However, some apparent host preferences have been demonstrated (e.g., Valtonen et al. 1997, Mikheev et al. 1998, 2000, Pasternak et al. 2000).

Most publications regarding host preferences of branchiurans concentrate on infection dynamics within just one or two host species (e.g., LaMarre and Cochran 1992, Mikheev et al. 1998, Pasternak et al. 2000), often in non-natural situations such as laboratory aquaria or fish farms (e.g., Hakalahti and Valtonen 2003, Mikheev et al. 2004). There is a noticeable lack of published information regarding the distribution and epidemiology of $A$. foliaceus in mixed species fish communities.

It is probable that, for behavioural and ecological reasons, some fish species are more likely to be infected by non-host-specific parasites than others. Bandilla et al. (2005) suggested that host behaviour leading to increased exposure to lice was the most likely mechanism leading to observed infection characteristics of Argulus coregoni Thorell on rainbow trout Oncorhynchus mykiss (Walbaum) from a Finnish fish farm.

On this basis we hypothesize that certain fish species are more likely to be infected with different life history stages of the non-host-specific ectoparasite, A. foliaceus, due to the increased likelihood of encounters related to species-specific ecological and behavioural 
traits. This study aims to use field observations of infection characteristics of $A$. foliaceus on several host fish species to highlight the importance of considering parasite ontogeny when looking at parasite distributions amongst hosts and also the importance of considering all members of a fish community when studying such an apparently non-host-specific parasite.

\section{MATERIALS AND METHODS}

Fish sampling. Sampling took place in one lake of a mixed species, freshwater, commercial fishery in SW England (OS grid reference: SX456751). This lake has a surface area of approximately 2 acres and an average depth of approximately $90 \mathrm{~cm}$. This man-made fishing lake was completed and opened to the angling public in 1995. Fish were sampled on nine occasions during the late spring and summer season, a period when A. foliaceus is known to be most abundant and when all life history stages are present (Walker et al. 2004). Fish were mostly sampled with angling techniques; samples of small fish inhabiting the dense weed beds of the shallow littoral zone were obtained with a standard pond net. During each sampling trip several different areas were fished and within each area anglers were fishing at several depths and locations during the course of the day. Standard angling methods were used for several reasons: i) the fishery owner wished it; ii) the authors felt this method of fish capture causes the least disturbance to the environment; iii) it did not cause excessive damage to the fins, scales, mucous layer and epidermis of the fish; iv) it reduced the risk of parasites being 'rubbed' off during capture; v) several regions of the fishery and several species of fish were targeted simultaneously by using several anglers. Upon capture all fish were placed on a pre-wetted, white mat (to aid spotting of dislodged parasites) and handled with wet hands to minimise damage to the epithelium and the protective mucous layer. The eyes of larger fish were covered with a damp cloth to calm the fish during parasite collection.

Parasite collection. The external surfaces, buccal and gill cavities of all fish were examined thoroughly for Argulus individuals which were subsequently removed carefully using a set of blunt forceps. The total number of parasites (referred to as "all lice" from here on) and the number from each age class (larval, juvenile and adult) collected from the fish was recorded along with the fish species they were taken from. Parasite life history stage was classified as larval, juvenile or adult according to descriptions by Rushton-Mellor and Boxshall (1994).

Data analysis. Parasite numbers from all nine sampling occasions were pooled to give an overview of the infection characteristics during the sampling period. Statistics were calculated using methods described by Rózsa et al. (2000) with Quantitative Parasitology 3.0 (QP 3.0; Reiczigel and Rózsa 2005). Descriptive statistics include prevalence (proportion of infected hosts amongst all hosts examined) with exact confidence limits and mean intensity (average number of parasites found on the infected hosts - zeros of uninfected hosts were excluded) with bootstrap confidence limits (BCa) as recommended by Rózsa et al. (2000). As measures of aggregation we calculated the Index of Discrepancy (D) as described by Poulin (1993) and tested the infection intensity frequency distribution to see how closely it fits a negative binomial distribution (k). All confidence intervals are given at the 95\% level unless otherwise stated.

Differences between host species numbers were analysed with ANOVA and Dunns post-hoc test using INSTAT. Chisquare test was used to test differences between prevalences as recommended by Rózsa et al. (2000). Bootstrap 2-sample ttest was applied to test for differences between mean intensities. This test is considered more appropriate for parasites due to the skewness of their distribution (Rózsa et al. 2000). A Brunner-Munzel test of stochastic equality was applied to test differences between parasite intensity distributions (Reiczigel et al. 2005).

\section{RESULTS}

\section{Fish species}

Eight species of fishes were encountered during the sample period: three-spined stickleback Gasterosteus aculeatus aculeatus L.; rudd Scardinius erythrophthalmus (L.); roach Rutilus rutilus (L.); gudgeon Gobio gobio gobio (L.); common bream Abramis brama (L.); tench Tinca tinca (L.); crucian carp Carassius carassius (L.); and common carp Cyprinus carpio carpio L. Not all species were equally represented in samples (Table 1 ) indicating that there are probably greater numbers of some species than others within the resident fish community. Rudd (24\%), carp (22\%), gudgeon (18\%) and roach $(13 \%)$ were the most abundant species in samples (Table 1).

\section{Infection data}

Fish lice (Argulus foliaceus) were found on all sampling days (identified with characteristics described by Fryer (1982). Of the 650 fish sampled, 241 were infected with $A$. foliaceus. Infection summary statistics for all, larval, juvenile and adult lice are summarized in Table 2. All the louse populations show infection intensity frequencies that exhibit an over-dispersed pattern with many fish harbouring low numbers and only a few fish with high numbers of lice. These data fit a negative binomial distribution in all cases (Fig. 1).

Water temperature during the sampling period ranged from a minimum of $15.5^{\circ} \mathrm{C}$ at the start of the sampling period to a maximum of $22.5^{\circ} \mathrm{C}$ at the end of the sampling period. The abundance of all lice and the different life history stages on the different fish species varied during the course of the sampling period (Fig. 2A-D). However, a general trend is apparent with larval and juvenile stages typically being more abundant on sticklebacks than other species throughout the sampling period (Fig. 2B, C). Adult lice, however, were consistently more abundant on carp and gudgeon, with sticklebacks sometimes appearing as an important host species (Fig. 2D). From the beginning of June until the end of the sampling period, larval lice exhibited a much greater abundance than adult lice and this pattern was similar for 
Table 1. The proportion of the sampled fish community made up by each species and the distribution of all lice (larval + juvenile + adult stages), larval lice, juvenile lice and adult lice on different host species.

\begin{tabular}{lcrrrc}
\hline \multirow{2}{*}{ Fish species } & \multicolumn{5}{c}{ Proportion (\%) } \\
\cline { 2 - 6 } & $\begin{array}{l}\text { Total } \\
\text { fish com. }\end{array}$ & $\begin{array}{l}\text { All } \\
\text { lice }\end{array}$ & $\begin{array}{l}\text { Larval } \\
\text { lice }\end{array}$ & $\begin{array}{l}\text { Juvenile } \\
\text { lice }\end{array}$ & $\begin{array}{l}\text { Adult } \\
\text { lice }\end{array}$ \\
\hline Stickleback & 8 & 32 & 83 & 26 & 9 \\
Rudd & 24 & 4 & 0 & 9 & 2 \\
Roach & 13 & $<1$ & 0 & 1 & 0 \\
Gudgeon & 18 & 18 & 10 & 19 & 22 \\
Bream & 6 & 6 & 0 & 5 & 11 \\
Tench & 4 & 2 & 0 & 2 & 4 \\
Crucian carp & 5 & 1 & 1 & 3 & $<1$ \\
Common carp & 22 & 37 & 6 & 35 & 52 \\
\hline
\end{tabular}

juvenile stages although their numbers did not increase until mid to late June. The abundance of all lice increased during the first half of the sampling period and then appeared to level off and even decrease towards the end of the sampling period. The abundance of larval and juvenile stages matched this pattern quite closely, however, the abundance of adult lice appeared to remain relatively stable throughout the sampling period.

Prevalence was highest for adult lice followed by juvenile and then larval lice. The prevalences of the different life history stages differed significantly (Chisquare $=112.75$, 2df; $\mathrm{P}<0.0001$ ). Lower average infection intensity typically coincided with higher prevalence. Mean infection intensity in larval stages was significantly higher than in adult stages $(t=-4.22$, 2-sided $\mathrm{P}$-value $<0.01)$ and juvenile stages $(\mathrm{t}=-3.85$, 2-sided $\mathrm{P}$ value $<0.01)$. Infection intensity for juvenile lice was also significantly higher than for adult lice $(\mathrm{t}=-2.18$, 2sided P-value $<0.05$ ). Infection intensity distributions of adult and larval stages and juvenile and larval stages also differed significantly (2-tailed P-values $<0.00001$ and 0.0001, respectively) but not between adult and juvenile stages (2-tailed P-value $=0.177)$.
Lice were not distributed evenly between the fish species and the distribution of larval, juvenile and adult stages showed differences in terms of their occurrence on different host species (Table 1). The majority of the lice sampled were found on carp and sticklebacks with a large proportion also being found on gudgeon (Table 1). Relatively few lice were observed on the other fish species caught. Larval lice were found predominantly on sticklebacks. Juvenile louse distribution approximates closely to that of all lice together, with carp and sticklebacks harbouring the majority of juvenile lice followed by gudgeon and again relatively few lice being found on the other host species (Table 1). Adult lice, however, were found predominantly on carp followed by gudgeon and then bream. Tench, crucian carp and bream samples were not subjected to further statistical analyses due to the low number of individuals sampled.

\section{Infection data for the stickleback population}

Of the 53 sticklebacks examined, 58\% were infected with $A$. foliaceus (Table 2). The whole louse population and the larval lice portion, fit the negative binomial distribution (Fig. 1). The juvenile and adult lice portions do not fit the negative binomial distribution. Lice infecting the stickleback population appear to be more aggregated in their distribution than the pattern for the whole fish community.

Prevalence ranged from the highest for adult lice to the lowest for juvenile lice. However, prevalences were not significantly different (Chi-square $=0.44,2 \mathrm{df} ; \mathrm{P}=$ 0.803 ). The mean infection intensity of larval lice was significantly higher than the mean infection intensity of juvenile and adult lice $(\mathrm{t}=-2.723,2$-sided P-value $<0.05$ and $t=-5.113$, 2 -sided $\mathrm{P}$-value $<0.001$, respectively). The mean intensity of juvenile lice was significantly higher than that of adult lice $(\mathrm{t}=-6.053$, 2-sided P-value $<0.0001)$.

Table 2. Mean and maximum intensity (I), prevalence and Index of Discrepancy (D) (after Poulin 1993), for all, larval, immature and adult lice are shown for the whole fish community and the stickleback, rudd, gudgeon and carp populations. Data for roach are not given due to the very low louse prevalence on this species. The 95\% confidence limits for each value are shown in parentheses.

\begin{tabular}{|c|c|c|c|c|c|c|}
\hline $\begin{array}{l}\text { Parasite } \\
\text { group }\end{array}$ & Parameter & $\begin{array}{l}\text { All fish } \\
(\mathrm{n}=650)\end{array}$ & $\begin{array}{l}\text { Stickleback } \\
(\mathrm{n}=53)\end{array}$ & $\begin{array}{l}\text { Rudd } \\
(\mathrm{n}=153)\end{array}$ & $\begin{array}{l}\text { Gudgeon } \\
(\mathrm{n}=119)\end{array}$ & $\begin{array}{l}\text { Carp } \\
(\mathrm{n}=140)\end{array}$ \\
\hline \multirow[t]{4}{*}{ All lice } & Prevalence & $37.1(33-41)$ & $56.6(42-70)$ & $8.5(5-14)$ & $57.1(48-66)$ & $65.7(58-73)$ \\
\hline & Mean I & $2.8(2.5-3.3)$ & $7.3(5.4-9.6)$ & $2(1.5-2.5)$ & $1.8(1.5-2.2)$ & $2.7(2.3-3.1)$ \\
\hline & Max I & 23 & 23 & 4 & 8 & 9 \\
\hline & $\mathrm{D}$ & 0.796 & 0.667 & 0.932 & 0.601 & 0.587 \\
\hline \multirow[t]{4}{*}{ Larval } & Prevalence & $3.8(2.6-5.7)$ & $28.3(18-42)$ & N/A & $3.4(1-8)$ & $2.9(1-7)$ \\
\hline & Mean I & $6.4(4.6-8.4)$ & $8.9(6.6-12.1)$ & N/A & $4.0(1.3-6.3)$ & $2.0(1.0-3.3)$ \\
\hline & Max I & 22 & 22 & N/A & 7 & 4 \\
\hline & $\mathrm{D}$ & 0.977 & 0.796 & N/A & 0.970 & 0.973 \\
\hline \multirow[t]{4}{*}{ Juvenile } & Prevalence & $17.4(14.6-20.5)$ & $24.5(15-38)$ & $7.2(4-13)$ & $24.4(17-33)$ & $28.6(22-37)$ \\
\hline & Mean I & $2.1(1.9-2.4)$ & $4.8(3.6-5.5)$ & $1.9(1.3-2.6)$ & $1.6(1.3-2.0)$ & $2.2(1.7-2.7)$ \\
\hline & Max I & 7 & 7 & 4 & 5 & 7 \\
\hline & $\mathrm{D}$ & 0.888 & 0.789 & 0.944 & 0.81 & 0.810 \\
\hline \multirow[t]{4}{*}{ Adult } & Prevalence & $24.8(21.5-28.2)$ & $30.2(19-44)$ & $2.6(1-6)$ & 39.5 (31-48) & $50(42-58)$ \\
\hline & Mean I & $1.8(1.6-1.9)$ & $1.5(1.2-1.9)$ & $1.3(1.0-1.5)$ & $1.3(1.2-1.4)$ & $2.1(1.8-2.5)$ \\
\hline & Max I & 7 & 3 & 2 & 2 & 7 \\
\hline & $\mathrm{D}$ & 0.825 & 0.735 & 0.971 & 0.663 & 0.662 \\
\hline
\end{tabular}



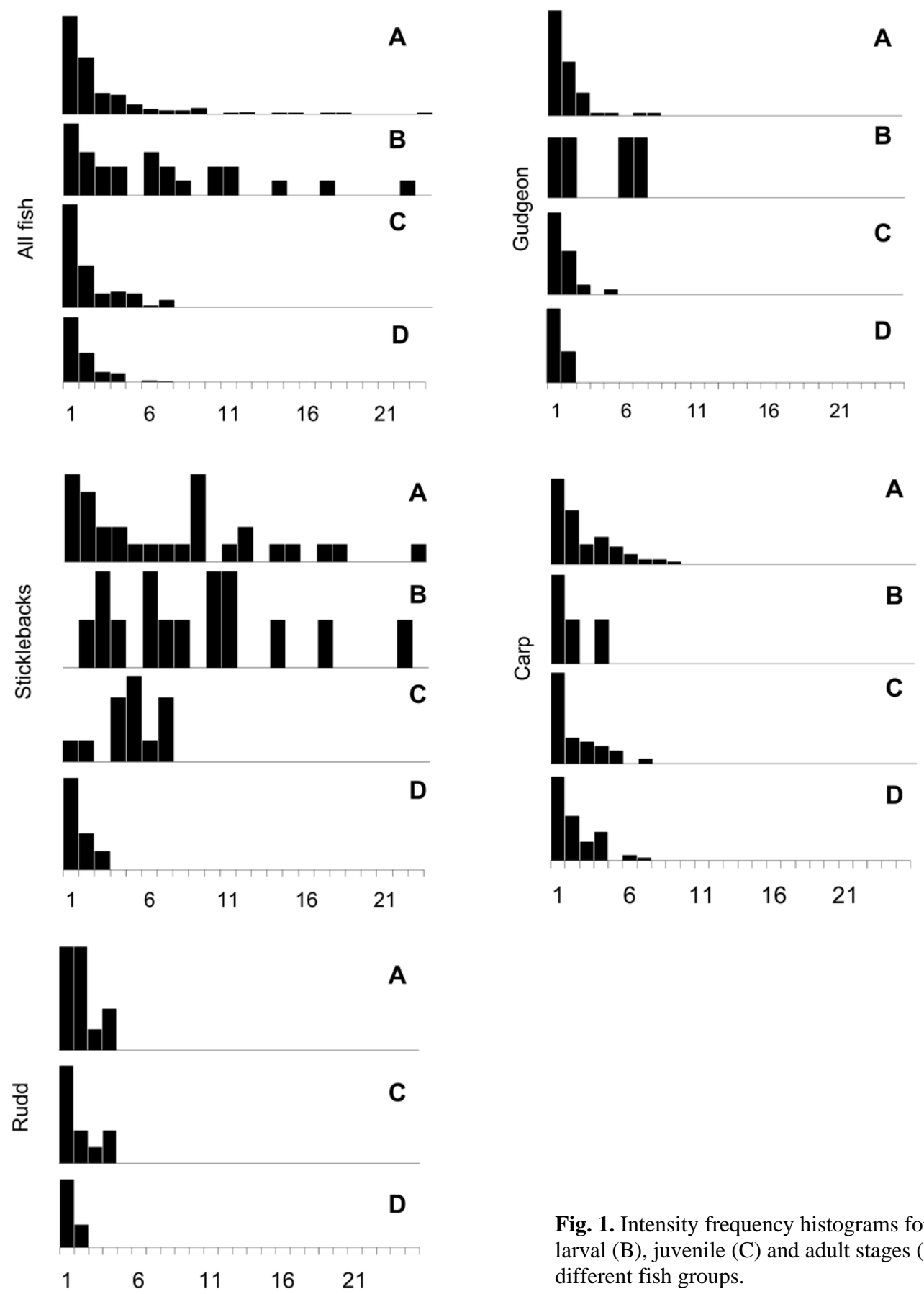

Fig. 1. Intensity frequency histograms for all lice (A), larval (B), juvenile (C) and adult stages (D) infecting different fish groups.

Aggregation was highest in larval lice followed by juvenile and then adult stages (Table 2). Infection intensity distributions of the three life history stages differed significantly in all cases (2-tailed P-values: adults versus larvae, $\mathrm{P}<0.001$; adults versus juveniles, $\mathrm{P}<0.001$; juveniles versus larvae, $\mathrm{P}<0.05)$.

\section{Infection data for the roach population}

Prevalence was very low $(3.5 \%, 0.001<95 \% \mathrm{cl}<0.1)$ with only 3 out of 85 fish harbouring lice. Two fish harboured one juvenile louse each and the third fish har-

boured one adult louse. Due to the extremely low numbers of lice statistical analyses were not possible.

\section{Infection data for the rudd population}

Of the 153 rudd examined, only $8.5 \%$ were infected with $A$. foliaceus (Table 2). The whole louse population and the juvenile portion fit a negative binomial distribution (Fig. 1). No larval lice were found on rudd and there were insufficient adult lice to test the intensity frequency distribution. Infection intensities were considered low in all cases (maximum of 4 lice per fish). 

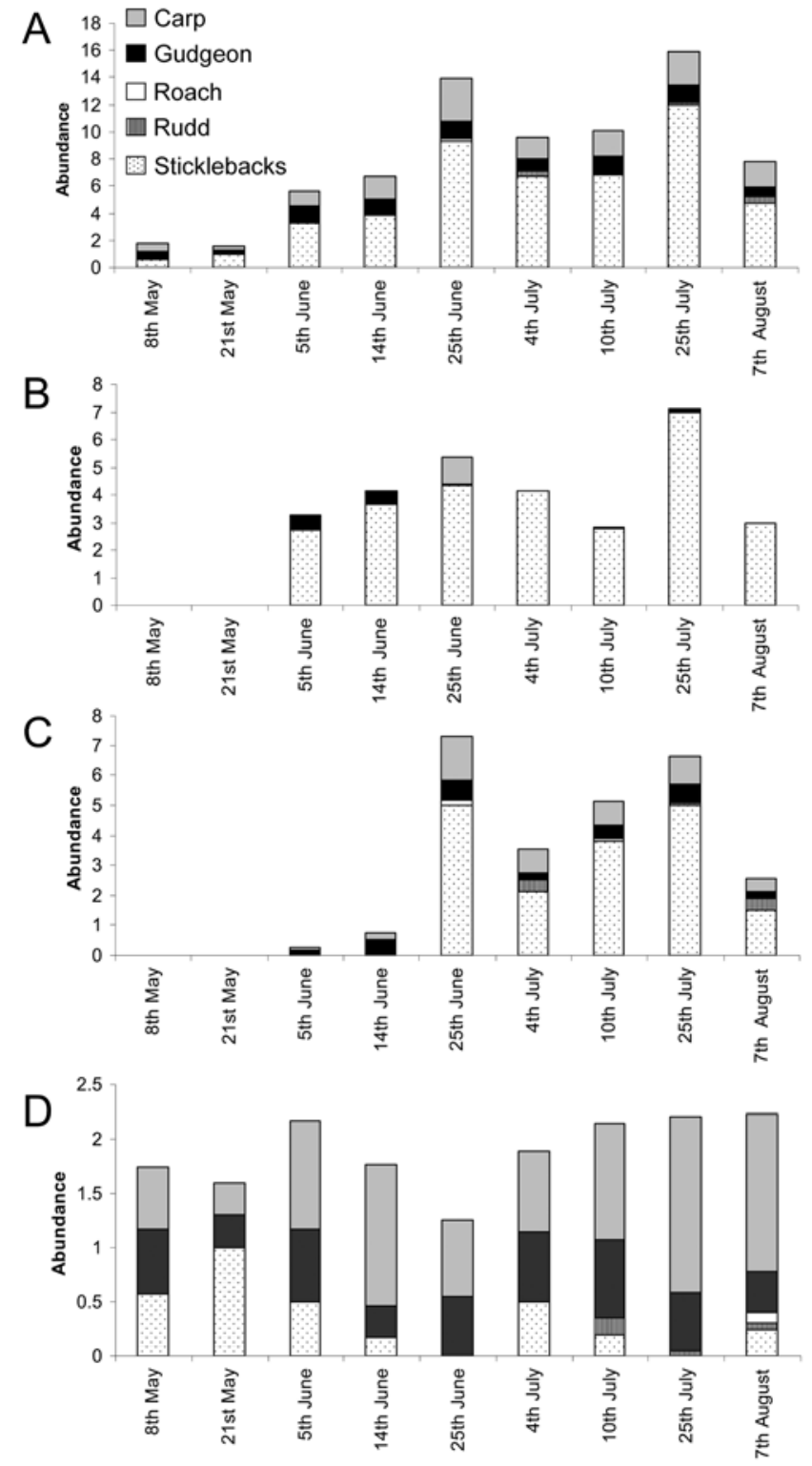

Fig. 2. Stacked bar charts showing the abundance of all lice (A), larval (B), juvenile (C) and adult stages (D) on five different fish species sampled on nine occasions.

Prevalence of the different life history stages did differ significantly (Chi-square $=12.819,2 \mathrm{df}$; $\mathrm{P}<0.005$ ) with juveniles exhibiting the highest prevalence. However, the prevalences were considered low $(<8 \%)$ in all cases. Juvenile louse mean infection intensity was higher than that of adults (Table 2) but the difference was not significant $(\mathrm{P}>0.05)$.

\section{Infection data for the gudgeon population}

More than half of the gudgeon sampled were infected with A. foliaceus (Table 2). In the case of all lice, larval and juvenile stages, the infection intensity frequency data fit a negative binomial distribution (Fig. 1).

Adult prevalence was highest followed by juvenile and then larval lice (Table 2). Prevalence of the different life history stages differed very significantly (Chi- square $=45.067$, 2df; $\mathrm{P}<0.0001)$. Larval lice exhibited the highest mean infection intensity followed by juvenile and then adult lice. However, mean intensities of the different life history stages did not differ significantly in all cases. Larval lice also exhibited the highest degree of aggregation, again followed by juvenile and adult stages (Table 2) but intensity distributions did not differ significantly.

\section{Infection data for the carp population}

Of the 140 carp sampled, 66\% were infected with lice (Table 2). The intensity frequency distribution of the louse population as a whole fitted a negative binomial distribution as did the juvenile louse portion (Fig. 1). Adult louse intensity frequency distribution did not fit a negative binomial distribution, however, and there were not enough categories of larval lice to test the fit.

Adult lice exhibited the highest prevalence followed by juvenile and then larval lice (Table 2). Prevalence of the different life history stages differed significantly (Chi-square $=78.885$, 2df; $\mathrm{P}<0.0001$ ). Mean infection intensities of the three life history stages were all very similar (Table 2) and did not differ significantly. Larval lice exhibited the highest degree of aggregation followed by juveniles and then adults (Table 2), however, the infection intensity distributions did not differ significantly.

\section{Between species comparisons}

The prevalence of all lice and of larval, juvenile and adult life history stages differed significantly between species in all cases (Chi-square $=172.242$, 4df; $\mathrm{P}$ $<0.0001)$. The infection intensity of all lice on sticklebacks was significantly higher than all other species (2sided P-values $<0.01$ in all cases). Mean infection intensity on roach was significantly lower than those of all other species (2-sided P-values $<0.03$ in all cases). Mean infection intensity on rudd was significantlyhigher than roach and sticklebacks (2-sided P-value $<0.03$ ) but not significantly different from gudgeon (2sided P-value $>0.1$ ). The mean infection intensity of carp was higher than that of rudd although the difference was only marginally significant (2-sided P-value = 0.085). Mean infection intensity on gudgeon was significantly lower than on sticklebacks and carp (2-sided $\mathrm{P}$-values $<0.03$ ) but not significantly different from rudd (2-sided P-values $>0.05$ ).

Only sticklebacks, gudgeon and carp harboured larval lice. Mean infection intensity of larval lice on sticklebacks was significantly higher than on gudgeon or carp (2-sided P-values $<0.05$, respectively). Mean infection intensity of larval lice on gudgeon was higher than that of carp (Table 2) but the difference was not significant (2-sided P-value $>0.05$ ).

All five species were infected with juvenile lice. However, only two roach harboured juvenile lice, therefore this species was not included in the statistical analysis. Juvenile louse infection intensity was signifi- 
cantly higher on sticklebacks than on all other host species (2-sided P-values $<0.05$, respectively). Juvenile louse infection intensity on rudd was slightly higher than on gudgeon and slightly lower than on carp but the differences were not significant (2-sided P-values $>0.05$, respectively). Infection intensity of juvenile lice on carp was slightly higher than on gudgeon and the difference was considered marginally significant (2-sided P-value $=0.06)$.

For adult louse infection intensity, roach were again excluded from statistical analysis as there was only one fish harbouring adult lice. Adult louse mean infection intensity on carp was significantly higher than on sticklebacks, rudd and gudgeon (2-sided P-values $<0.05$, respectively). Mean infection intensity of adult lice on sticklebacks was slightly higher than on rudd or gudgeon but the differences were not significant (2-sided $\mathrm{P}$ values $>0.05$ ). Infection intensities of adult lice on rudd and gudgeon also did not differ (2-sided P-value $>0.05$ ).

We also tested the intensity distributions of lice, and of the different life history stages, between the different species. Roach were excluded from all analyses, except that of all lice, due to the low number of infected fish for this species. In addition, rudd were excluded from analyses of larval lice because no rudd were found with this parasite life history stage. Intensity distributions of all lice were significantly different between all species (2-sided P-values <0.05) except between rudd and gudgeon and rudd and carp (2-sided P-values $>0.05$ ). The difference between larval lice intensity distribution on sticklebacks and carp was significant (2-sided P-value $<0.05$ ), between gudgeon and sticklebacks the difference was marginally significant (2-sided P-value $=0.06$ ) and the difference between carp and gudgeon was not significant (2-sided P-value $>0.05$ ).

Juvenile lice intensity distributions on sticklebacks differed significantly from rudd, gudgeon and carp (2sided P-values $<0.01$ in all cases). Intensity distributions on rudd did not differ significantly from gudgeon or carp (2-sided P-values $>0.05$ ) and intensity distributions did not differ between carp and gudgeon either. Finally, intensity distributions of adult lice differed significantly between carp and gudgeon (2-sided P-value <0.01) but not between any of the other species. However, the difference between sticklebacks and carp could be considered marginally significant (2-sided P-value $=0.07)$.

\section{DISCUSSION}

A range of different regions and depths around the lake were sampled at several different times during the day and on each sampling trip several angling methods were employed to ensure that any bias in fish species caught could not be attributed to sampling locality or sampling technique. Very heavily infected fish are likely to be lethargic and spend less time feeding than lightly infected or uninfected individuals (Wendelaar Bonga 1997, Walker et al. 2004), which would reduce the likelihood of these individuals being caught. No moribund or dead fish were observed during the whole of the sampling period and the fishery owner had not reported such occurrences. Infection levels were generally not high enough to cause serious effects, e.g., morbidity and lethargy associated with epizootics. Lice could be dislodged during capture of the fish, but Bower-Shore (1940) observed that a fast-flowing stream of water in the laboratory did not dislodge adult parasites therefore the chosen sampling methodology probably did not result in significant losses of lice during fish capture. No data are available to determine if the attachment strength differs between life history stages. An alternative sampling technique that would exclude all of the above possible biases or provided more reliable data is currently unavailable.

The abundance data hint towards a trend of certain fish species being favoured as hosts by different life history stages of Argulus foliaceus. The relative abundance of larval and juvenile stage on the different host species does not appear to vary greatly throughout the sampling period although their numbers do vary considerably. However, the abundance of adult stage on sticklebacks does vary noticeably throughout the sampling period. Adult lice appear to be more abundant on sticklebacks approximately 4 weeks prior to the first big peak in larval lice numbers and approximately 3 weeks prior to the second big peak in larval lice numbers. Our own laboratory observations have shown that $A$. foliaceus eggs can hatch in only 18 days at $20^{\circ} \mathrm{C}$ and 28 days at $15^{\circ} \mathrm{C}$ (unpublished data). Therefore, it appears that adult lice may utilize sticklebacks as a temporary host whilst they move into shallow water to deposit their eggs which subsequently hatch after 2-6 weeks (depending on temperature) resulting in the observed peaks in larval lice abundance that we observed.

If $A$. foliaceus and the various host fish species were evenly distributed within the water body, parasite distribution should be related to the number of available hosts from each species. However, in terms of total numbers of lice, parasite distribution amongst the host community does not appear to be related to the number of available hosts from each fish species in our study.

All fish species sampled are known to be potential hosts for A. foliaceus (Kennedy 1974). The infection data for the fish community as a whole showed that adult louse prevalence (i.e., proportion of the community harbouring adult lice) was significantly higher than both juvenile and larval louse prevalence. Larval lice in contrast, however, showed the highest mean intensity and adult lice the lowest mean intensity. This shows a trend of larval lice having a more aggregated distribution than the other life history stages but becoming more dispersed as they mature. Eggs of $A$. foliaceus are typically deposited in clumps or, more commonly, parallel rows with as many as several hundred eggs in a clutch (Mikheev et al. 2003, Walker et al. 2004, Kearn 2004). 
A firm substrate such as a plant stem or surface of a stone, is required for egg deposition (Kearn 2004), and therefore certain areas where a large surface area of suitable substrate is available may become 'hot-spots' for infection of fish with larval lice, leading to an aggregated distribution on hosts that occur in these regions. The intensity frequency data (Fig. 1) support this, showing that several individuals were infected with relatively high numbers of larval lice (up to a maximum of 22 lice!) and very few fish with more than 4 adult lice.

As a generalist parasite, $A$. foliaceus probably does not actively discriminate between fish species. However, if certain regions are indeed hot-spots for infection with larval lice then fish that frequent these regions are more likely to become infected with larval lice than fish that generally occur in other regions of the water body. Mikheev et al. (2003) suggested that most freshwater fishes concentrate close to the shore in late spring and early summer for spawning and foraging thereby increasing the risk of exposure at least to larval and adult female parasites. Urho (1996) showed that A. foliaceus occurs almost exclusively in the littoral zone of a lake during the summer although no distinction was made as to what life history stage was encountered. We found that adult $A$. foliaceus were more common in open water habitats (data not shown) but it should be noted that our study was conducted in a very small, shallow (mean depth $<1 \mathrm{~m}$ ) pond the whole of which is probably representative of a larger lake's littoral zone.

Prevalence of the parasite's three life history stages on sticklebacks did not differ significantly. However, mean infection intensities did, with larval lice showing much higher intensities than adult and juvenile stages, and adults showing the lowest. Sticklebacks are known to inhabit the shallower, more sheltered regions of stillwaters (Davies et al. 2004) particularly during the spring and summer periods for reproduction purposes and because of higher food abundance (Mikheev et al. 2003, Davies et al. 2004). These sheltered, littoral regions (e.g., reed beds, pier supports, etc) are also the areas generally chosen for egg deposition by adult female A. foliaceus (Walker et al. 2004). This would place sticklebacks at high risk of infection by larval lice and our data and those of Walker et al. (2007) support this.

In aquaria, $A$. foliaceus showed a preference for juvenile roach over perch under light conditions, with the reverse being found under dark conditions (Mikheev et al. 1998). In the field, perch exhibited higher infection levels than roach (Valtonen et al. 1997). In our study we only encountered three roach harbouring lice, only one of which was an adult louse. Mikheev et al. (2000) later demonstrated that $A$. foliaceus also changes its hunting strategies depending on whether conditions are light or dark. The small lake sampled for our study was very turbid and light intensities were probably quite low only several centimetres below the surface. This is typical of lakes containing many carp due to their feeding habits (Davies et al. 2004). Herter (1927) suggested that $A$. foliaceus avoids the surface zones with too much light and this could be to avoid the 'sensory overload' mentioned by Mikheev et al. (2003). This hypothesis was deduced from lice in glass aquaria. However, rippling on the water surface may cause light reflections resulting in similar confusing effects for the lice. This effect may cause behavioural changes in the lice resulting in avoidance of this zone. If this behavioural change does occur then lice will be subjected to lower light intensities resulting from high turbidity and this could influence $A$. foliaceus to adopt the 'dark-hunting-strategy' which may not favour the location of roach as suggested by Mikheev et al. (1998). In addition, roach tend to show a fairly ubiquitous distribution within stillwaters with no obvious microhabitat preference (Davies et al. 2004). Larval lice especially are more likely to occur in regions with vegetation, or around other structures more common in shallow littoral zones, due to the egg deposition habits of adult female lice. Juvenile and adult stages may be more dispersed if lower light intensities do encourage a shift towards the 'dark-hunting-strategy'. Then fish that are swimming in close proximity to the lake bottom and which are not highly active in their behavioural habits (e.g., gudgeon, carp and sticklebacks) are more likely to become infected than those showing a more pelagic or surface dwelling habit (e.g., roach and rudd).

Whilst the prevalence of $A$. foliaceus on rudd is more than double of that on roach, at $8.5 \%$ it is still a very small portion of the population that is infected. Rudd tend to swim close to the surface in proximity to, but not necessarily within, vegetation stands (Davies et al. 2004). As we stated earlier, larval lice are more likely to be found within vegetation stands rather than outside of them and all lice are likely to be more common near the bottom (Herter 1927) in a different vertical zone to that typically inhabited by the rudd. Rudd are relatively active, fast swimmers when compared with species such as gudgeon and sticklebacks. The relatively slow swimming speed of $A$. foliaceus (especially the larval stage) may mean that rudd provide a difficult target for lice to locate and successfully attach to.

More than half of the gudgeon population was infected with lice. Gudgeon are typically benthic feeders (Davies et al. 2004), so are more likely to encounter lice showing the 'dark-hunting-strategy' and swimming closer to the bottom away from the bright, reflective, surface zones. Gudgeon are a slow swimming, shoaling species often occurring in large shoals which would facilitate parasite transmission by dispersing them amongst the population. Thus, we would expect a high prevalence but not necessarily a high intensity, and this is indeed what we observed. The higher intensity of larval lice is concurrent with a low prevalence suggesting that a small number of fish had encountered a hot- 
spot where larval lice had emerged and the parasites become more dispersed within the host population as they mature.

Argulus foliaceus is also called the 'carp louse' and it is not surprising therefore that the highest prevalence of lice was observed on carp. As with other host species, adult louse prevalence was higher than that of larval and juvenile stages and this, combined with a relatively low average intensity, shows adult lice to be rather overdispersed amongst the host population. Interestingly larval lice exhibited a very low prevalence and intensity. Carp are known to be fairly ubiquitous in their distribution within this lake and are probably relatively more active than sticklebacks and gudgeon. This higher level of activity would make it more difficult for larval lice to locate and successfully attach to carp.

The differences between species were significant for several infection variables. The prevalence of the three life history stages differed significantly between species in all cases. Significant differences were also found for mean infection intensities (although the differences were only marginally significant for larvae), suggesting average infection intensities are dependent upon host species. Intensity distributions also support the hypothesis, formulated from the prevalence and average infection intensity data, that $A$. foliaceus exhibits a stagespecific distribution within the host community. Mean intensities of all lice, and the larval and juvenile stages, on sticklebacks were significantly higher than on all other host species. This indicates that this species exhibits habits that increase its exposure to young $A$. foliaceus (Walker et al. 2007).

The physical and immune response characteristics of the host fish probably play a role in determining infection characteristics. Ecological and behavioural characteristics of the host species may create different opportunities for different life history stages of $A$. foliaceus to infect them and this is the more likely driving force behind the infection characteristics observed in natural systems. Mikheev et al. (2003) similarly suggested that it is the interplay between host and parasite behaviour that determines host-searching success of the parasite and subsequent observed parasite infection patterns. The range of species found harbouring $A$. foliaceus supports the view that this is a generalist parasite species and patterns of parasite distribution within mixed host species communities are likely to be determined by hostparasite encounter frequencies. Whilst the mechanisms employed for host location (e.g. olfaction, vision, mechanosensation) have been investigated previously (Mikheev et al. 1998, 2000, 2003, 2004) information is still lacking on how these sensory mechanisms may influence host selection by this parasite and by each of its life history stages.

The observed differences in abundance between the life history stages is probably attributable to the fact that larval, juvenile and adult lice are known to spend different amounts of time free swimming (Stammer 1959, Pasternak et al. 2000, Mikheev et al. 2003). Adult male lice must leave their hosts to locate mates and females must do so in order to deposit eggs (Walker et al. 2004). Further studies examining these off-host periods of lice, in particular for the adult stage, are required to determine the degree to which these off-host periods influence louse distributions in the wild.

Differences in parasite prevalence and/or intensity on one host species at one time does not necessarily demonstrate a preference for this species (Lester 1984), but may in fact reflect differences in the level of exposure of this species to the parasite due to other factors such as the relative abundance or distribution of that host species. In conclusion, $A$. foliaceus distributions within a community differ between host species and parasite life history stages and that ecological/behavioural traits of both host and parasite play a significant role in determining these distributions.

Acknowledgements. The authors wish to thank the members of the EU Training network, PARITY, for advice and comments during informal presentations of these data. Thanks are also extended to Ben Holbrook, Anthony Oxley, Iain Russon and Stewart Walker for assistance with fish sampling and parasite counting. In addition, the authors wish to thank the owners and anglers at Mile Mead fishery for their assistance and tolerance. This is Centre for Wetland Ecology publication number 486 .

\section{REFERENCES}

BANDIlla M., HaKalahti T., Hudson P.J., VAltonen E.T. 2005: Aggregation of Argulus coregoni (Crustacea: Branchiura) on rainbow trout (Oncorhynchus mykiss): a consequence of host susceptibility or exposure? Parasitology 130: 169-176.

BARBER I., HoARE D., KRAUSE J. 2000: Effects of parasites on fish behaviour: a review and evolutionary perspective. Rev. Fish Biol. Fish. 10: 131-165.

BENZ G.W., Bullard S.A., Dove A.D. 2001: Metazoan parasites of fishes: synoptic information and portal to the literature for aquarists. Regional Conference Proceedings of the American Zoo and Aquarium Association 2001. AZA, Silver Spring, MD, pp. 1-15.

BOWER-SHORE C. 1940: An investigation of the common fish louse, Argulus foliaceus (Linn.). Parasitology 32: 361-371.
DAVIES C., SHelly J., HARDING P., MCleAN I., GARDINER R., PEIRSON G. 2004: British Freshwater Fishes - the Species and their Distribution. Harley Books, Essex, 184 pp.

FRYER G. 1982: The parasitic Copepoda and Branchiura of British freshwater fishes: A handbook and key. Freshwater Biol. Assoc. 46: 1-87.

GURNEY R. 1948: British species of the fish louse of the genus Argulus. Proc. Zool. Soc. Lond. 118: 553-558.

HAKALAHTI T., VALTONEN E.T. 2003: Population structure and recruitment of the ectoparasite Argulus coregoni Thorell (Crustacea: Branchiura) on a fish farm. Parasitology 127: 7985.

HERTER K. 1927: Reizphysiologische Untersuchungen an der Karpfenlaus (Argulus foliaceus L.). Z. Vgl. Physiol. 5: 283-370. 
Holland C.V., KenNEDY C.R. 1997: A checklist of parasitic helminth and crustacean species recorded in freshwater fish from Ireland. Proc. R. Irish Acad. 3: 225-243.

KaBATA Z. 1985: Parasites and Diseases of Fish Cultured in the Tropics. Taylor \& Francis, London, 318 pp.

KEARN G.C. 2004: Leeches, Lice and Lampreys: A Natural History of Skin and Gill Parasites of Fishes. Springer, Dordrecht, The Netherlands, $432 \mathrm{pp}$.

KENNEDY C.R. 1974: A checklist of British and Irish freshwater fish parasites with notes on their distribution. J. Fish Biol. 6: 613-644.

KolLATSCH D. 1959: Untersuchungen über die Biologie und Ökologie der Karpfenläuse (Argulus foliaceus L.). Zool. Beitr. 5: 1-36.

LAMARRE E., COCHRAN P.A. 1992: Lack of host species selection by the exotic parasitic crustacean, Argulus japonicus. J. Freshwater Ecol. 7: 77-80.

LESTER R.J.G. 1984: A review of methods for estimating mortality due to parasites in wild fish populations. Helgol. Meeresunters. 37: 53-64.

Lester R.J.G., Roubal F.R. 1995: In: P.T.K Woo (Ed.), Fish Diseases and Disorders. Volume 1: Protozoan and Metazoan Infections. CAB International, Wallingford, pp. 475-598.

MiKheEV V.N., Mikheev A.V., PAsternaK A.F., VALtonen E.T. 2000: Light-mediated host searching strategies in a fish ectoparasite, Argulus foliaceus L. (Crustacea: Branchiura). Parasitology 120: 409-416.

MikheEV V.N., PASTERnaK A.F., VALtonen E.T. 2003: How do fish ectoparasites Argulus spp. (Crustacea: Branchiura) match with their hosts at the behavioural and ecological scales? Zh. Obshch. Biol. 64: 238-247.

MiKHEEV V.N., PASTERNAK A.F., VALTONEN E.T. 2004: Tuning host specificity during the ontogeny of a fish ectoparasite: behavioural responses to host induced cues. Parasitol. Res. 92: 220-224.

MiKHEEV V.N., PASTERNAK A.F., VALTONEN E.T., LANKINEN Y. 2001: Spatial distribution and hatching of overwintered eggs of a fish ectoparasite, Argulus coregoni (Crustacea: Branchiura). Dis. Aquat. Org. 46: 123-128.

MiKHEEV V.N., VALTONEN E.T., RinTAMÄKI-KINNUNEN P. 1998: Host searching in Argulus foliaceus L. (Crustacea: Branchiura): the role of vision and selectivity. Parasitology 116: 425-430.

Nolan D.T., VAN DER SAlm A.L., WeNDElaAR BONGa S.E. 2000: The host parasite relationship between the rainbow trout (Oncorhynchus mykiss) and the ectoparasite Argulus foliaceus (Crustacea: Branchiura): epithelial mucous cell response, cortisol and factors which may influence parasite establishment. Contrib. Zool. 69: 57-63.
Øines O., Simonson J.H., KNUTSEN J.A., HEUCH P.A. 2006: Host preference of adult Caligus elongatus Nordmann in the laboratory and its implications for Atlantic cod aquaculture. J. Fish Dis. 29: 167-174.

PASTERNAK A.F., MiKHEEV V.N., VALTONEN E.T. 2000: Life history characteristics of Argulus foliaceus L. (Crustacea: Branchiura) populations in central Finland. Ann. Zool. Fenn. 37: 25-35.

Poulin R. 1993: The disparity between observed and uniform distributions: a new look at parasite aggregation. Int. J. Parasitol. 23: 937-944.

PoUlin R., FITZGERALD G.J. 1987: The potential of parasitism in the structuring of a salt marsh stickleback community. Can. J. Zool. 65: 2793-2798.

POULIN R., FITZGERALD G.J. 1988: Water temperature, vertical distribution, and risk of ectoparasitism in juvenile sticklebacks. Can. J. Zool. 66: 2002-2005.

REICZIGEL J. 2003: Confidence intervals for the binomial parameter: some new considerations. Stat. Med. 22: 611-621.

ReICZIGEL J., RózsA L. 2005: Quantitative Parasitology 3.0. Budapest. Distributed by the authors.

REICZIGEL J., ZAKARIAS I., RÓZSA L. 2005: A bootstrap test of stochastic equality of two populations. Am. Statist. 59: 156161.

ROBERTS L.S., JANOVY J. 1996: Foundations of Parasitology, 5th Ed. WCB Publishers, New York, USA, 659 pp.

RÓZSA L., REICZIGEL J., MAJOROS G. 2000: Quantifying parasites in samples of hosts. J. Parasitol. 86: 228-232.

RUSHTON-MELLOR S., BOXSHALl G.A. 1994: The developmental sequence of Argulus foliaceus. J. Nat. Hist. 28: 763-785.

STAMMER H.J. 1959: Beiträge zur Morphologie, Biologie und Bekämpfung der Karpfenläuse. Z. Parasitenkd. 19: 135-208.

URHO L. 1996: Habitat shifts of perch larvae as survival strategy. Ann. Zool. Fenn. 33: 329-340.

VALTONEN E.T., HOLMES J.C., KOSKIVAARA M. 1997: Eutrophication, pollution and fragmentation: effects on parasite communities in roach (Rutilus rutilus) and perch (Perca fluviatilis) in four lakes in central Finland. Can. J. Fish. Aquat. Sci. 54: 572-585.

WALKeR P.D., ABbink W., VAN DER Velde G., WendelaAR BONGA S.E. 2007: Size matters: stickleback size and infection with Argulus foliaceus (L., 1758) (Branchiura, Arguloida). Crustaceana 80: 1397-1401.

WalkeR P.D., FliK G., WendelaAR Bonga S.E. 2004: The biology of parasites from the genus Argulus and a review of the interactions with its host. Symp. Soc. Exp. Biol. 55: 107129.

WENDELAAR BONGA S.E. 1997: The stress response in fish. Physiol. Rev. 77: 591-625.

Accepted 28 March 2008 